\title{
Managerial challenges to promoting competency-based intellectual capital in emerging market economies - Developing a framework for implications
}

\author{
Authors: Sateesh Shet, Manlio Del Giudice, and Hussain Gulzar Rammal
}

Accepted for publication in Journal of Intellectual Capital on 28 April 2021

DOI: 10.1108/JIC-01-2021-0018

\begin{abstract}
Purpose: This study explores the challenges experienced by managers in adopting competency modeling $(\mathrm{CM})$ and recommends an approach to overcome these challenges in promoting competency-based intellectual capital in organizations.

Design/method/approach: Using in-depth interviews with organizational practitioners in India, this study identifies the challenges of competency modeling in emerging market economies.

Findings: This study identifies nine contextual and eight non-contextual challenges in implementing CM practices in organizations. The framework addresses the CM challenges using direction setting, negotiation and selling, and monitoring and control dimension of implementation with behavioral, operational, and change alignment aspects of CM. The framework proposes a checklist for stakeholders to help them diagnose and analyze the gaps in effective $\mathrm{CM}$ implementation.

Originality: The framework suggests a checklist for stakeholders to help diagnose and analyze the gaps in effective Competency Modeling adoption. This framework will assist the change management practitioners, HR leaders, Organizational Development consultants, and practitioners as a toolkit to address the challenges in the people management intervention.

Keywords: Competency Modeling, Intellectual capital, human capital, competencies, organizational challenges, organizational development, change management, implementation framework.
\end{abstract}




\section{Managerial challenges to promoting competency-based intellectual capital in emerging market economies -developing a framework for implications}

\section{Introduction}

Maintaining a competitive edge is the ultimate goal of every business organization. Products, pricing, technology, location, and physical resources are tangible and quantifiable sources that help organizations retain this advantage. Increasingly, organizations' people management capability, which is primarily intangible, is also considered a source of competitive advantage (Chadwick and Flinchbaugh, 2020). An organization's collective stock of employee competencies constitutes its human capital, while its internal-external culture and network of relationships form its social capital. The alignment of human capital with an organization's mission and strategy influences intellectual capital (IC) and creates a competitive advantage (Lee, 2009). While organizations adopt different strategies to improve human capital, the practice of competency modeling $(\mathrm{CM})$ has been the most widely applied. Competency modeling involves integrating the competencies/competency model into organization practices to achieve strategic outcomes from a human capital perspective. We argue that to promote IC, the organization's people practices, specifically $\mathrm{CM}$ practices, need to be effective.

However, organizations are not successful in adopting $\mathrm{CM}$ owing to various challenges (Hollenbeck et al., 2006). According to the Brandon Hall Group's 2016 Talent Management Survey, $69 \%$ of the organizations stated their competency management was "somewhat" or "not at all" effective, and around $72 \%$ acknowledge that the alignment of competency development with business goals was weak. The other challenges listed were "not prioritizing the competency initiative," "lack of understanding on the criticality of competencies," and "lack of investment in competency deployment." Further, Deloitte-DDI Consulting (2015) highlighted the "language used in competency descriptors" and "too many competencies" as challenges in deployment. Other studies have assessed that most organizational leaders could not use CM as they are complex and theoretical (BTS, 2016), and organizations are not wellequipped to implement CM (Stone, Webster \& Schoonover, 2013). The list of organizations that have found the implementation challenging include Aetna Life, Xerox, Bank One, Tampa Elective, HP, and AT\&T. Organizations' practitioners continue to inquire, "Why do organizations struggle to implement CM?" "What is the effective framework to implement CM in organizations?" and "How can organizations address challenges during CM implementation?" However, there are no definite prescriptions to these questions or any specific guidelines from management research for practitioners and academicians to apply.

Competent resources characterize organizations with a high-performance culture. Therefore, having a workforce with such prescribed capabilities is essential for an effective organization. Organizations seek to develop processes and systems across all levels, departments, units, and geographies to build a competency-based culture. However, many organizations are ineffective in executing the $\mathrm{CM}$ effectively as required. Thus, researchers and practitioners, both consulting and industry professionals, aimed at bridging this gap. We focused on three 
significant aspects. First, we considered the resource-based view of human resource management (HRM), where using complementary resources is important (Barney, 1991). This requires treating human capital is a resource (in our context, CM practices act as an enabler); and combining this resource with HR practices to contribute to organizational outcomes (in this case, IC) through vertical and horizontal alignment (Soderquist, Papalexandris, Ioannou, and Prastacos, 2010; Vos et al., 2015). Extant studies on competency development have mainly analyzed the HRM and not the IC outcomes. In particular, linking CM with IC is not explored adequately from the integration perspective. Therefore, this research attempts to connect CM systems and IC and recommends ways for how practitioners can implement it in organizations. Second, despite practitioners acknowledging the need for competencies, consulting firms provide the most relevant information on existing studies. There is little information regarding $\mathrm{CM}$ integration and research-based processes used for forming deductions and explanations on this aspect. Therefore, we try to address this drawback and supplement research-based evidence supporting CM integration in organizational practices.

Given the complexity of the topic, a detailed understanding of CM integration is paramount, and this is possible through the qualitative method applied in this study (Eisenhardt \& Graebner, 2007; Yin, 1994). Third, we consider organizations as the units of analysis and investigated $\mathrm{CM}$ integration challenges from an organizational practice perspective. The following fundamental research questions guided our study:

What are the challenges and issues of applying CM in organizations? How can organizations successfully integrate CM in organization processes to promote IC?

We analyze the CM challenges from contextual and non-contextual aspects using a qualitative research approach by studying the phenomena from the perspective of India's organizations. Based on the learnings, we propose a framework for CM implementation. The framework considers the direction setting, negotiation and selling, and monitoring and control dimensions of implementation with behavioral, operational, and change alignment aspects of organizational CM. This study's findings have implications for researchers and consulting practitioners who need to understand the complex challenges and systematic approach to implementing people management initiatives in organizations. Theoretically, we contribute in linking competencies with IC and discuss managerial challenges in CM as a body of knowledge in organization development intervention.

\section{Linking competency modeling to intellectual capital}

Competency models comprise the abilities, skills, knowledge, and other traits needed for superior performance in a job (Long, Ismail, \& Amin, 2013; Shet et al., 2019). Literature evidence that employees demonstrating competencies contribute to superior performance (Spencer \& Spencer, 1993; Bartram, 2004); this, combined with CM practices, provides a competitive edge for organizations (Campion et al., 2011). CM helps organizations align their operations and initiatives to the overall business strategy (Campion et al., 2020; Shet et al., 2017). The vertical and horizontal alignment of competencies with organizational strategic 
objectives and functional goals ensures IC's creation. The collective knowledge, skills, and attitude (KSA) ensure contributing to intangible assets like IC (Paoloni, Coluccia, Fontana, \& Solimene, 2020). The firm's organizational capability is improved as CM aligns an individual with job, role, and function, thus creating IC clusters at the leadership, specific function, or organization's specific capability. CM promotes communication in all directions (downward, lateral, and external communication) within the organizations (Friedman, 2019) by removing hierarchical and functional barriers. With the help of innovation competency, organizations develop patents and new products contributing to the IC of organizations (Papa, Dezi, Gregori, Mueller \& Miglietta, 2018). Hence, competency development is not limited to any single aspect and covers a broad range of systems, processes, and organizational strategic areas that promote IC (Brawner, 2019; Garman et al., 2018).

IC in organizations can be broadly categorized as human capital, structural capital, and relationship capital. Human capital is one of the significant elements that influence IC in organizations that includes the implicit knowledge that exists in the employees' minds (Guo, Jasovska, Rammal, \& Rose, 2020). Being intangible, human capital cannot be easily measured or codified (Pasban \& Nojedeh, 2016). Employee knowledge and skills are under scrutiny in competency-based human capital, as there is a need to update these aspects continuously. Structural capital denotes the processes, databases, and supportive infrastructure of the firm that act as an aid to the human capital in performing its functions. Organizations can practice competency-based IC development by focusing on structural capital (Allameh, 2018).

Reliable structural capital is necessary for organizations to utilize human capital (Nourani et al., 2018). The development of human capital creates adequate structural capital, which, in turn, promotes the IC of the organization. Relationship capital mainly focuses on the organization's relationship with the stakeholders, partners, suppliers, and customers. It means that relationship capital deals with inter-organizational relationships. It encompasses the relationship between the organization and the customers, competitors, and suppliers. Managers need to be trained on the significance of relationship capital for an organization (Kwok et al., 2019). Human capital in the form of competencies influences in developing relationship capital, which, in turn, promotes IC for the organization. In its broad context, IC can be defined as the overall value that an organization has for its employees' knowledge and skills (Salvi et al., 2020). Thus, we argue that synergistic effects of competencies develop human capital, relationship capital, and structural capital, with all channelizing the efforts for IC creation.

One of the critical features of IC is its intangibility (Gogan et al., 2016). Hence, it is challenging to determine its value to the organization. Hiring candidates with the right managerial competencies, capable of maintaining good relations with stakeholders, can generate innovative ideas for the organization. Hiring employees with the right managerial competencies is challenging; Likewise, if suitable candidates are not employed, the training programs intended to make the employees competent would be insufficient. This reemphasizes the close link between CM and IC development in organizations. As these two elements are deeply connected, it is evident that $\mathrm{CM}$ challenges reflect in IC development. If the managers fail at motivating the employees, neither their skillsets will be enhanced, nor their involvement in the organization will increase. This is another pertinent managerial challenge 
in organizations that assert the significance of having managerial competencies. Another common challenge associated with IC development in organizations is the lack of sufficient communication mechanisms. The communication mechanism should be seamless, enabling smooth interaction between the subordinates and the management and vice-versa. IC mostly dwells within the employees' brains in the form of knowledge needed to complete the job. If this knowledge is not recorded or communicated to the higher authorities, it will be wasted (DuHadway et al., 2018). This insists on the need for communication as a significant managerial competency and ensuring all the enablers in the organizations in the form of $\mathrm{CM}$ practices promote communication competency. An effective $\mathrm{CM}$ practice addresses such challenges by ensuring that employees demonstrate the required behaviors critical to human capital development, leading to IC.

Although competencies are driven by individual behavior, organizations need to establish systems and processes to drive these behaviors toward organizational objectives. As such, organizations initiate $\mathrm{CM}$ in different people practices to reap strategic benefits (Klink and Boon, 2003). For example, a manager demonstrating the competency "relationship building" promotes repeat business and increases market share, which attains "relational capital" for the organization. Organizations can achieve those specific objectives, such as innovation capital, relational capital, etc. if their competency model and practices are effectively integrated into the organization's people management practices. For example, to promote innovation capital using CM, this process needs to be integrated into selecting and recruiting employees who meet the minimum prescribed competency behavior or in the Performance Management to assess, evaluate, and provide feedback on this competency. However, integrating CM into organizational practices is a complex process. The challenge is to integrate the people's capability with that of the organizations. Especially when people are connected to roles, functions, strategy, culture, and processes, resulting in outcomes in business performance; besides this, $\mathrm{CM}$ is a continuous process, and it passes through many organizational dynamics at different phases in an organization's lifecycle. The gray areas of execution, non-written processes, and implicit leadership are some of the interesting dynamics that are never discussed but form a significant CM implementation element.

\section{Research design}

This research uses a qualitative cross-sectional response to assess the factors influencing CM in organization practices. This study focuses on understanding the challenges of applying $\mathrm{CM}$ in organizations and identifying strategies for its successful implementation for promoting IC. The qualitative research method is deemed as most appropriate for addressing the how and why questions. Because of the study's exploratory nature, we adopted the semi-structured in-depth interview technique, and the researchers sought critical information on the issues and challenges of CM. This helped us to gain a deeper understanding of the phenomena through interview observations. Organizations can be hesitant to share details of their failure. Thus, we attempted to use the interview to discuss the dimensions of challenges in implementing CM related to employees, processes, budgets, capabilities, management support, etc. 
A combination of purposive sampling and snowball sampling was used to select the study respondents. A sample frame was created by listing the organizations implementing CM practices. The sample consists of 18 organization development managers, talent and engagement managers, HRBP, and senior-level professionals from other functions who are part of the competency development in those organizations. To avoid sampling bias with heterogeneous organizations (a combination of $\mathrm{MNC}$, Indian, business segments), the respondents' background forms the right mix as a sample (see Table 1 for the respondents' demographic details). These respondents were selected as they are part of both large- and medium-sized organizations in terms of the nature of the business. To gain the respondents' confidence during the interviews, the interviewees were briefed on the scope and the significance of the research and how this research problem of CM persists, and how their contributions will be of immense help.

$<$ Table 1: Demographics of respondents $>$

As the respondents had distinct professional backgrounds, i.e., not just from the HRM domain, we sought to explore the challenges to CM implementation from a change agent perspective in organizations. As each interview required considerable time, the interviews were conducted after prior appointments. For other locations, we sent the questions for discussions in advance, followed by a telephonic interview. On average, each interview lasted 40 minutes, and specifically for conglomerate organizations, it took 90 minutes. The language used for the interview was English. The questionnaire was prepared in agreement with three experts (academic, consulting, and industry professionals) in CM. Discussions with these experts helped structure the questionnaire with three sections to explore; first, demographics; second, the journey of CM to achieve the strategic objectives; and third, questions related to challenges and issues of $\mathrm{CM}$ to develop IC. The researchers prepared multiple questions for probing and prompting to ensure all aspects of the research areas are discussed in length. The interview flow would start with "what has worked well" in the context of CM and followed by which objectives were still not met by CM. As the respondents were experienced professionals, they would elaborate on the critical aspects of CM pertaining to their organization.

The interviews recorded with each interviewee were transcribed verbatim and reproduced in a spreadsheet to organize the data for analysis. We adopted Creswell's (2008) analysis process, which starts with transcripts followed by coding, theming, and the dimension of themes. The data showed some typical phenomena and a few exceptional cases, which are organizationspecific. Data was collated on a spreadsheet after each interview, and the transcript was assigned a code. We assessed the data using an inductive approach, i.e., looking for or identifying the common themes (Miles and Huberman, 2014). As this research aims to determine and understand which factors are linked with the implementation challenges of competencies, the researchers started by looking for various themes that addressed and helped explore these broad issues extensively. We took a constant comparative approach by integrating the researchers' emergent theoretical ideas and prior research (Strauss and Corbin, 2015; Miles and Huberman, 2014; and Golden-Biddle and Locke, 2007). The researchers observed and analyzed evidence of many different resemblances or similarities among the participant responses. Two researchers were involved in developing and generating the coding 
that enabled them to capture these systematically. Further, the researchers observed the common themes or categories gradually. Data collection and analysis was ceased when theoretical saturation was reached after the systematic coding of 18 interviews and no other new ideas were being generated (Golden-Biddle and Locke, 2007).

\section{Analysis of Findings}

Our thematic outcomes evidenced the challenges of CM into contextual and non-contextual factors. The contextual factors are specific to $\mathrm{CM}$ initiatives, while non-contextual factors are evidenced in any change management interventions in the people management areas. We discuss each of these themes (Table 2), followed by a framework to address these challenges.

<Table 2: Factors influencing CM implementation>

\subsection{Contextual Challenges.}

\subsubsection{Inadequate HR proficiency in implementation:}

External consultants design CM practices, and HR members struggle to acquire the implementation capability of CM. Generally, organizations believe that HR practitioners are proficient in adopting CM practices, which is not always true. HR members are incapable of conducting behavioral event interviews (BEI) for employee selection. (Hollenbeck et al, 2006). HR practitioners lacked much-needed proficiency to integrate CM in different sub-HR systems, as in this scenario, they are unable to understand how competency-based interviewing works. HR professionals lack the required management skills as internal experts. The absence of HR skills - credible advisor, strategic orientation, technology focus, business acumen, and HR business partner (HRBP) impedes them from being internal change agents (Ngo, Jiang, and Loi, 2014). Further, the HR capability on CM varied between corporate HR and location HR. There was an absence of knowledge and skills transfer from corporate HR to location HR.

\subsubsection{Unaddressed organization-specific challenges:}

Deploying CM interventions implies tackling organization-specific challenges. An entity or department may effectively implement a CM within an organization, whereas others may find it difficult. For instance, in an R\&D organization, the focus is on functional competencies rather than behavioral competencies. The lack of balance between these is evident in technology or knowledge-oriented organizations. Some organizations assume that their workforce understands the competencies uniformly across all locations, which may not be accurate (Muratbekova-Touron, 2009). Employees often complain that the competency model needs to be customized to the local language and explained clearly with limited technical jargon. Often employees have difficulty understanding psychological nomenclature in the competency model. CM implementation tends to lose quality, efficiency, and effectiveness due to a few inept HR members. Human Resource Management System (HRMS) may not support the changes required for competency-based practices in specific functional modules. Understanding and addressing these organization-specific challenges in $\mathrm{CM}$ is vital for practical CM. 


\subsubsection{Lack of specificity of competencies:}

Organizations develop competency models for different management hierarchy layers - top, middle, and junior management; however, such multiple models require more effort to execute. Employees regularly complain about the vast number of competencies used in CM. Some practitioners assert that the list of competencies is incomplete, as managers cannot describe all the competencies required for a job. It is challenging to ensure that the competencies identified are relevant to all geographies and business verticals. Organizations struggle to develop maturity in competencies and neglect to review the list of competencies for their relevance over time. (Audenaert, Vanderstraeten, Buyens, and Desmidt, 2014).

Furthermore, there are no guidelines on how many competencies are apt for employees and a job. It is posited that people foster and attain competencies at their own pace because of their preferences, time constraints, and available learning experiences. Employees assume themselves to be not yet competent instead of "incompetent". The concept of competency is regarded as egalitarian and premised because every individual can develop the right set of competencies with the right motivation, context, and practice.

\subsubsection{Lack of contextual relevance of competencies:}

Consultants involved in the design of CM build excessive expectations in the behavioral indicators without reviewing the contextual aspects. Some leaders ignore the alignment of competencies with an organization's business strategy and its contextual requirements and objectives. For example, organizations do not provide global exposure to employees even when their "operational excellence" competency states as "develops the global benchmarks standards of operational excellence in their business". Although businesses prefer common competencies, they are used across the globe irrespective of the local organizational context. Both competencies and organizations are dynamic and hence struggle to meet the expectations of the organization stakeholders. A competency model must strike the right balance between simplicity, complexity, and relevance; a simple model may not address the larger purpose, whereas a complex model may be challenging to use. If an organization does not align its $\mathrm{CM}$ practices with the contextual challenges, $\mathrm{CM}$ will fail to get into mainstream practice, unlike in HRM or any other people practices.

\subsubsection{Improper use of proficiency level of competencies:}

Determining the proficiency level of competencies is challenging, as it must fit with the organizational structure, scope, and expectations of the role (Sanchez and Levine, 2009). Some organizations use three levels to categorize employee proficiency in competencies- mastery, comprehension, and awareness- while others use five. Employees may find it difficult to understand these levels and struggle to use them, especially during competency-based rewards and recognition, compensation, or career or succession planning. Even though these aspects look simple and easy, any dissatisfaction or confusion in interpretation by employees will lead to their reluctance to use $\mathrm{CM}$.

\subsubsection{Lack of validity in competencies:}


Organizations are analyzing the reliability and validity of $\mathrm{CM}$ at multiple levels organizational, functional, departmental, and at the job level. The issue of the validity of competency as a cluster of competencies is also controversial. Often, there is no correlation between the elements of competency and performance criteria (Soderquist, Papalexandris, Ioannou, and Prastacos, 2010). For instance, a key performance criterion for a sales role is influencing customers through effective persuasion and relationship building. But if a competency model of a sales role does not capture this, there will be a disconnect between stated and actual practice. In such a scenario, incorporating too many generic competencies is ineffective. Organizations are also not practicing the pilot testing of competencies on relevant samples for validation. They do consult with a subject-matter expert or relevant stakeholders to determine the relevance of their competency model.

\subsubsection{Conflicts in the universal application of CM:}

In large organizations, HR departments use their trusted methods to evaluate employees and do not necessarily use CM. In a Total Quality Management(TQM)-driven organization, the business excellence model has a distinct methodology for collecting information on people's capabilities. In comparison, a plant head may decide role attributes for production staff based on instinct or his/her experience in previous companies. Similarly, the recruitment team may consider a set of traits to evaluate candidates if they find that their competency models are not suitable. This may arise in other recruitment contexts, as well. Standard psychometric tools have their own set of traits that may not sync with an organization's competencies. In some organizations, there are resemblances between organizational values and competencies. For example, 'customer focus' is both value and competency, even though their definitions may be more or less the same. Thus, an organization must discuss such conflicting issues during CM.

\subsubsection{Issues assimilating conventional HR with competency-based HRM (CHRM):}

An organization's HR systems and practices often impact the competency system's effectiveness more than the competency model. Although CHRM is a new buzzword for HR practitioners, organizations find it challenging to replace a conventional system with a CHRM for several reasons. First, at any point in the organization, there are new employees and existing employees who are not keen on learning many aspects of CHRM. Second, there is no fixed scope, content, curriculum, standard operating procedures (SoP), dos, and don'ts. Third, The absence of objectives of CHRM in each of its functional sub-areas.

In some cases, CM implementation in HRM processes may also lack consistency in the functional areas' implementation. Moreover, developing HRM processes around a limited set of competencies by considering each competency as a separate whole is debatable. Each organization varies in the practice of $\mathrm{CM}$ with its various functions and teams and may have standalone processes that are difficult to replace (Catano, Darr, and Campbell, 2007; Rodriguez et al., 2002). HRM support is imperative for CM, as HRM practices are connected to employees in established policies and procedures.

\subsubsection{The criticality of competencies:}


Specific job profiles demand more focus on critical competencies. Similarly, a reporting manager may set a preference for a subordinate's competencies. Technology companies or CEOs with a tech background always prioritize technical and functional competencies over behavioral competencies. The criticality of competencies is problematic as practitioners prioritize organizational capabilities, functional requirements, and individual specifications. Although a sales manager's competencies are defined, their existing capabilities may vary byproducts, geographies, and expecting "same behavioral descriptions" may not work.

Moreover, criticality also changes, as per the need of the organization. Job-specific competencies for roles such as 'health and safety' or 'brand communication' manager may also vary from $\mathrm{CM}$ as they are unique job profiles. In short, allowing too many competency templates tends to confuse employees. Sometimes, CEOs use core competency terminologies that may be unusual from their competency model. For instance, tech-savvy CEOs may indicate "technology focus" as a core competency, but an existing competency model may not have this competency. Annual reports, marketing brochures, and published reports use different terminologies, such as strength, USP, philosophy, and credo, to convey the same message as of competency. Too much jargon for the same behaviors often leads to confusion, and CM may lose its focus.

\subsection{Non-contextual Challenges.}

\subsubsection{Ineffective communication:}

Organizations do not customize communication strategies on competencies. Typically, an email on the rollout of CM is considered an effective way to communicate, without an inquiry on whether employees accept it across the regions and at different levels. Further, there is no clarity on who has to communicate, whether the CEO, HR, or the reporting manager. In some cases, both individuals and organizations may not be convinced sufficiently on competencies' perceived benefits to advance the initiative forward. Most of the time, communication is not integrated with HRM practices and is mainly carried during specific activities. This results in a lack of continuum in practice. Many employees seek to question the competencies of their job role on where they stand against competencies and how they can make a difference in their job. However, such individual aspects are missing in competencies, and organizations infer that employees have understood and endorsed the CM. There is no mechanism either by a dipstick survey or through manager feedback to monitor the competency modeling practices' effectiveness. The overall communication approach must be on a consultative basis to ensure that it impacts all organization employees.

\subsubsection{Lack of stakeholders' involvement:}

Not involving an organization's stakeholders, such as top management, line managers, and local HR managers, act as a barrier for competency deployment. Often, it is viewed that HR practitioners only use CM but not line managers. Sometimes, organizations do not involve reporting managers of high-potential employees during Assessment Centers (AC) initiative. This has led to dissatisfaction for not involving them. Consequently, they do not mentor high potential employees and create L\&D plans for them. Excluding top management at the initial 
stage could lead to their disinterest in CM. This may lead to the non-prioritization of this $\mathrm{CM}$ initiative by employees as they follow their leaders.

\subsubsection{Lack of leadership drive:}

Organizations have recognized the absence of a leadership drive concerning CM. Besides the $\mathrm{CEO}$ and $\mathrm{HR}$, the push from the functional heads, unit heads, and reporting managers is not evident, and employees perceive that their bosses do not have the intent. Transferring the CM implementation ownership to an Organization Development/Talent Manager does not fulfill the requirements since each team needs to identify a resource to drive this in their respective unit, department, or function. The absence of the project manager's scope and role in the CM project implementation is also a reason for weak implementation. While implementing CM in MNCs, there is a disconnection between the corporate policy guidelines and the existing reality at the plant units or location offices. For business leaders, financial goals are an essential priority. It is a prerequisite to balance different organizational goals and establish competencies as a priority for both the employees and the organization (Vakola, Eric Soderquist, and Prastacos, 2007). Hence, the leaders' morale needs to be consistently high for this initiative.

\subsubsection{No link to vision and strategy:}

While competency interventions start positively, the results are vague as leaders do not strategize $\mathrm{CM}$ with milestones and responsibilities. People-oriented practices demand significant time and effort, and organizations do not invest sufficiently as equivalent to marketing or financial strategies. Aligning competencies with organizational strategy can be demanding. The drawbacks of not implementing CM need to be highlighted with business cases on the current organizational issues. There are often no reward and recognition systems to motivate employees to develop and acquire the required competencies.

Moreover, organizations do not consider learning, such as what has worked well for other organizations that have implemented CM. Most consultants paint a rosy picture of "creating internal leaders," "high potential talent bench strength," and "breakthrough performance," which may not be possible for all organizations. The financial, motivational, intellectual, and innovation must illustrate the CM benefits(Shet, 2019). Competency interventions need to be implemented one at a time to ensure a successful rollout. Furthermore, there may be confusion as to whether competency is an HR tool or a business imperative. The HR practitioners argue that $\mathrm{CM}$ is a management tool, while line managers consider it an HR tool. They claim that CM's content is described in business terminology and helps organizational strategy and performance. Hence, they argue it is not an HR tool. Further, HR advocates that this initiative is driven by a business excellence team, strategy team, or functional head for effective implementation.

\subsubsection{Resistance from employees:}

Employees are often hesitant to be appraised on competencies. They also disagree on the "360degree competency-based feedback" since they are acquainted with goal-based appraisal ratings and feedback. Such resistance mechanisms need to be addressed by the organization by 
strengthening the credibility of CM with stated benefits. The resistance can be at the leadership or the employee level. Sometimes, resistance is at a particular unit or location or on specific policy components of CM (Gentry and Sparks, 2011).

\subsubsection{Inadequate cost-benefit analysis:}

Organizations proceeding without an adequate analysis of cost versus benefit may disrupt the implementation of CM. This includes resource cost, cost of project execution, and the effort required to evaluate pre-and post-interventions. Consulting organizations advocate using the off-the-shelf competency model as a cost-effective tool; however, they may not serve the purpose. Since managers play a crucial role in implementing $\mathrm{CM}$, they must be alerted to competency practices' benefits. Thus, instead of directly embarking on a CM program, it is more viable to conduct a realistic cost-benefit analysis of the program. Organizations invest in the design of CM but are unable to envisage the future costs associated with CM initiatives. In some cases, ACs and leadership development investment to identify employees for succession planning has not been evaluated with a cost-benefit analysis.

\subsubsection{Inadequate organizational readiness:}

An organization's internal units and its employees may not always be ready for competency implementation. This may be a lack of trust between the employees and management, the timing of the rollout of the competency intervention, or ongoing restructuring within the organization (Berraies, Hamza, \& Chtioui, 2020). Thus, the timing, situation, and emotional and physical readiness at the leadership, functional, or departmental levels are prerequisites for successful CM implementation. Besides, the scale in terms of size of the organization also needs to be considered as effective implementation involves organizational readiness for a particular business, location. Hence, CM initiatives do not progress if the organization fails to understand the stakeholder's state of mind.

\subsubsection{Inadequate budgets and resources allocation:}

Most organizations spend on competency model creation but fail to support subsequent implementations, which require substantial investments. Competency-based interventions are expensive in terms of both money and resources. A considerable amount of time and money is invested in creating a competency model and rolling out different initiatives. Training programs based on competencies need to be customized and need to be effectively facilitated by competent trainers. Similarly, in an Assessment Centre (AC), leadership development based on competencies involves a substantial investment with external experts as a part of the initiative. Inadequate budget allocation on competency practices leads to non-realization of objectives. Therefore, top management buy-in is vital for achieving the required budgetary assurance. Hence, organizations need to allocate adequate resources and budgets to develop competencies aligned with their organizational strategy.

We have discussed the challenges experienced by practitioners in CM implementation. Having examined each of these elements, we now propose a framework to address these challenges in the discussions section. 


\section{Discussions}

This study evidenced two dimensions of challenges in the form of contextual and noncontextual factors influencing the implementation of CM practices in organizations, which hinders the IC growth. The thematic analysis identified various factors an organization should address to reap the benefits of CM to enhance human capital, which influences the relational capital and structural capital, thus leading to the formation of IC. Organizations either use highly complex concepts such as strategies or focus on low-level tasks, tactics, and activities for the effective implementation of CM. During such strategic implementation of any intervention, practitioners usually ignore the middle ground, i.e., the intermediate-level integrating activities into a consistent whole. The practical implementation of CM processes and procedures takes considerable time; they capture the relationships among different activities, often lost in a single, one-time approach implementation. CM practices are imbibed with organizational factors such as strategy, resources, structure, people, and culture. Hence, a process-oriented approach motivates thinking in this context instead of a single-event straightforward implementation, thus addressing all the challenges related to $\mathrm{CM}$ implementation.

\subsection{Framework for Competency Modeling Implementation}

The integrated framework suggested below comprises diagnostic questions that enable leaders and managers to evaluate the effectiveness and efficiency of $\mathrm{CM}$ implementation in organizations. The processes of direction setting, selling and negotiation, and control and monitoring need to align (Table 3) with the change, operational, and behavioral aspects of implementing CM.

<Table 3: Framework for CM implementation>

\subsubsection{Direction setting process}

Direction setting is the foremost process in CM implementation. This entails charting out the organization's course of action, ensuring alignment, and mobilizing complete support for the $\mathrm{CM}$ objectives. In this phase, the goals of the CM are set. The organizational leader or manager communicates through different modes to have the same understanding of CM. This usually happens during the annual strategy or goal-setting processes to ensure that $\mathrm{CM}$ is linked to business plans. However, at this stage, the actual work plan on CM is unstructured and informal and depends on the organization's specific managerial execution and context. The directionsetting process entails learning about the firm's context regarding what works (or what does not) on CM issues, probing continuously, setting a vision for employees, developing a strategy, motivating employees, communicating information, and establishing processes for CM. The manager or leader needs to choose a suitable approach in setting the direction for CM. Simultaneously, organizations need to develop HR capability among their resources to implement CM initiatives. 


\subsubsection{Negotiation and selling process}

Once an organization sets the direction or path, the negotiation and selling processes are vital for effective CM implementation. An initiative on CM depends on cross-functional groups for execution. In such relationships, formal authority is generally lacking; therefore, leaders or managers should devise other means or methods to ensure cooperation. This requires building a network of contacts and working with the right people to negotiate the different trading terms for the present and future interactions and connections. Different approaches or methods are used to gain support and cooperation, which include creating interdependence. A formal authority to compel the $\mathrm{CM}$ does not succeed, and leaders use the negotiation and selling approach to persuade the stakeholders. Successful and effective negotiation necessitates understanding others' weaknesses and strengths, priorities, agendas, and the relationships they consider essential. Middle managers should convince subordinates of CM's importance by creating projects that shed light on its importance and urgency and bring CM together to ensure that employees accept and support the exercise. Even CEOs must engage in selling CM to gain support from employees for their plans and strategies. Though these challenges are unwritten or unstated, leaders must pass through this phase to successfully implement CM.

\subsubsection{Monitoring and control process}

The organization undertakes the monitoring and control process to ensure that $\mathrm{CM}$ interventions are as planned. Such activities help identify issues with implementing CM, develop and initiate action plans, and reinstate the organizational equilibrium because business environments are essentially unstable. Leaders recognize the deficiencies of CM by gathering information through their networks, analyzing data, making observations, and using formal organizational processes such as variance-against-plan reporting. Effective monitoring is structured with what to measure, how to gauge when to measure, and who will measure the objectives of CM. Monitoring activities involve the support of HRM subsystems. This phase also includes the course correction of issues such as validity and criticality of competencies and eliminates confusion in other areas that influence CM.

We discuss the elements of this framework for the successful implementation of CM for leaders to practice. Leaders or managers involved in $\mathrm{CM}$ need to assess whether the organization has a clear direction for strategic change organization using CM. The organization's leaders need to guide by influencing stakeholders to bring the most required change element by adopting CM. During such a process, they should ensure that the initiative's capability is available among HR members. Leaders also need to address the difficulties envisaged in adopting CM in their organizational context. They need to identify the resistance from employees to CM by asking about the issues that influence them and the organization and discuss possible ways to mitigate them. Leaders need to ask, "is everyone in the organization convinced of the rationale for the change in using CM?" By raising this question and by involving the stakeholders, the leaders can address any resistance by negotiating and selling the benefits of CM to both individuals and the organization. Further, leaders need to assess whether management, HR, and others are aware of implementing the change using CM. The role of HR practitioners is crucial to integrate CM with HRM. 
Further, the relevance of CM in a particular organization needs to be highlighted to ensure that it is adequately monitored. By integrating CM with HRM, the identified HR members can control the defined process of bringing changes through CM. Each stakeholder needs to ask, "Has the organization set clear goals for strategic and operational performance using CM practices?" The leadership in an organization needs to convey the goals of the CM through effective communication. Besides, operational issues experienced during the adoption of $\mathrm{CM}$ need to be addressed to set the proper direction and align CM practices to deliver strategic and operational performance. It is equally crucial that HR leaders check whether the organization has acquired the resources and required consensus from both upstream and downstream departments. As CM is spread across the organization at all levels, leaders need to provide adequate resources and negotiate with stakeholders to reach a critical consensus between top management, unions, and other organizational stakeholders. Both management teams and HR functions must know how their CM plans and processes match organizational performance. $\mathrm{CM}$ is a continuous process based on the feedback of what works and what does not work. It needs to be redefined to ensure that $\mathrm{CM}$ drives organizational performance continuously. For this, aspects such as consultative communication involving stakeholders must be considered. The acceptance of the actions of leaders during CM adoption is essential. Leaders' actions also need to be credible during the implementation of $\mathrm{CM}$ to ensure that initiatives are monitored and effectively controlled to achieve the identified objectives.

\subsection{Implications}

This framework has two primary uses for organizations and leaders. First, it helps organizations decide how, where, and when to intervene during CM initiatives. Organizations need to focus on each question in the different columns of the framework to identify the most likely source of difficulty and determine correct remedial actions. Also, as decision-making is a behavioral concern, managers should focus on each of the third column's questions for diagnosing issues. The answers to these questions will provide a clear picture of whether the difficulties or challenges can be traced to unclear or ineffective concepts. Regardless of whether managers or leaders require focused real-time monitoring and feedback or whether the challenges result from current practices or low awareness of $\mathrm{CM}$, this framework offers a clear and powerful tool to identify and determine the underlying issues with CM implementation and address them accordingly.

Second, the framework helps leaders identify their weaknesses and strengths. Setting the direction, selling and negotiation, and control and monitoring are separate processes, and some leaders are equally skilled in all these processes. Leaders can determine their improvement areas by checking across the framework and asking the relevant questions for diverse businesses or organizational activities and functions. For instance, to evaluate the directionsetting skills, a manager may assess different change initiatives within the company to determine if the rationale for change is evident. They may also assess various operational processes under their purview to check whether clear goals have been set. They may also review different communication and decision-making processes to determine if the approach to $\mathrm{CM}$ has been clearly stated. Too many negative answers in the checklist indicate that the 
leader may need to improve their direction-setting, negotiation, or monitoring skills. Thus, this framework provides a clear perspective on $\mathrm{CM}$ challenges while also offering practical guidelines.

Competency-based human capital development focuses on the leadership skills and attributes of the employees. Insufficient experience in leadership can impact the performance of the organization in the long run. Without sufficient managerial skills, sales would decline, and organizations would find it challenging to get repeated business from the same customers. Likewise, productivity declines as the workers are not sufficiently motivated. It is also difficult for the employees to maintain a cordial relationship with the organization and remain committed to the firm if the leaders are not capable (Fitri et al., 2019). Relationship capital, which is one of the elements of IC, indicates the organization's relationship with the customers, vendors, and other external parties. With adequate relationship capital, the customers are satisfied, and the company secures repeated business (Shan et al., 2020). It focuses mainly on customer loyalty and customer relationship. Managers who possess these competencies are capable of contributing to the IC of the organization. Organizations need managers who contribute to their core competencies, enhancing their human capital and collective human capital contributing to IC capital (Dumay \& Guthrie, 2017; Hussinki et al., 2017). Companies can improve IC by focusing on relationship management competency. For instance, if the sales manager has a good relationship management competency, he/she would be able to acquire repeated business from the same customer (Ji \& Ma, 2019).

The competency mapping influences the organization's vision, business plans, strategic priorities, and goals. The gaps in the competencies are fulfilled with adequate training for the managers to carry out their duties and provide sufficient motivation for the rest (Hanna et al., 2016). The training programs are designed such that the employees' competencies have a longterm impact and can be converted into IC (Jordão \& Novas, 2017). Competency mapping clarifies the essential competencies and the likelihood of these competencies being transformed into the organization's IC (Massaro et al., 2018). The main objective of competency-based human capital is to provide competitive advantages. The competitive advantages help in increased revenue, customer retention and create new and innovative products. Competencybased human capital differentiates between the personal competencies and knowledge competencies as human capital elements contributing to a firm's IC (Boon et al., 2018). Hence, focusing on each employee's competencies will help promote IC (Bamel et al., 2020).

\subsection{Limitations}

Some limitations we noticed are, the study was limited to select organizations based in India. With qualitative research, we focused on in-depth interviews to examine the managerial challenges. Similarly, such studies can be done with quantitative approaches if organizations are willing to share the response. We discussed the phenomena after CM has been rolled out; an action study during the implementation of CM may help identify new phenomena. 


\subsection{Future research}

To progress this domain of competency-based IC, we propose several avenues for future research. Researchers can study the conceptual framework of competency-based IC with the antecedents and outcomes. The framework presented in this study can be further empirically validated with different variables influencing IC. While this research evidenced the factors influencing IC's CM practices, a separate study using multi-criteria decision-making can be examined to understand each of these factors' impact and which elements are critical. The effect of CM can influence specific competencies that influence the IC. The role of leadership, line manager, HRM, or people function as a moderator or antecedent to IC can be examined further. An action study within an organization examines the micro aspects such as role, structure, performance, compensation, rewards, and other various factors influencing individual competencies having IC as an outcome can be examined.

\subsection{Conclusion}

Successfully implementing CM is crucial for an organization's IC. The most important aspect is to combat the critical challenges encountered during CM implementation, whose success hinges on addressing challenges in these three processes: direction setting, negotiation and selling, and monitoring and control. When organizations understand these challenges' criticality, practitioners can address them proactively, thus reaping the benefits of CM and justifying the investment. As most line managers adopt a theoretical approach to $\mathrm{CM}$, this study provides valuable practical inputs to deploy $\mathrm{CM}$, transforming the organization into an IC successfully. Thus, in this article, we elaborate on the CM challenges and recommend a framework that can be used by both organizations and leaders to address CM challenges for promoting IC.

\section{References}

Akkermans, J. and Tims, M. (2017), "Crafting your career: How career competencies relate to career success via job crafting”, Applied Psychology, Vol. 66 No. 1, pp.168-195.

Allameh, S.M. (2018), “Antecedents and consequences of intellectual capital”, Journal of Intellectual Capital, Vol. 19 No. 5, pp. 858-874

Audenaert, M., Vanderstraeten, A., Buyens, D. and Desmidt, S. (2014), "Does alignment elicit competency-based HRM? A systematic review", management revue, Vol. 25 No. 1, pp.5-26.

Bamel, U., Pereira, V., Del Giudice, M. and Temouri, Y. (2020), "The extent and impact of intellectual capital research: a two decade analysis", Journal of Intellectual Capital, ahead-of-print: https://doi:10.1108/jic-05-2020-0142

Berraies, S., Hamza, K.A. and Chtioui, R. (2020), "Distributed leadership and exploratory and exploitative innovations: mediating roles of tacit and explicit knowledge sharing and organizational trust", Journal of Knowledge Management, ahead-of-print: https://doi.org/10.1108/JKM-04-2020-0311 Boon, C., Eckardt, R., Lepak, D.P. and Boselie, P. (2018), "Integrating strategic human capital and strategic human resource management", The International Journal of Human Resource Management, Vol. 29 No. 1, pp.34-67. 
Brawner, K., (2019), "Standards Needed: Competency Modeling and Recommender Systems", in International Conference on Human-Computer Interaction (pp. 179-187). July. Springer, Cham.

Brulhart, F., Gherra, S. and Marais, M. (2017), “Are environmental strategies profitable for companies? The key role of natural competences from a resource-based view", Management Decision, Vol. 55 No. 10, pp. 2126-2148,

Brandon Hall (2016), Report on Competency Management: The Essentials for Better Business Results. Archived from:

https://www.brandonhall.com/mm5/merchant.mvc?Screen=PROD\&Product_Code=IP16++Competency+Management

BTS (2016), Competency Models Are Failing. Why? Archived from: https://www.bts.com/newsinsights/articles/competency-models-are-failing-why

Cabrilo, S. and Dahms, S. (2018), "How strategic knowledge management drives intellectual capital to superior innovation and market performance", Journal of Knowledge Management, Vol 22 No 3, pp. 621-648.

Campion, M., Fink, A., Ruggeberg, B., Carr, L., Phillips, G. and Odman, R., (2011), "Doing Competencies Well: Best Practices in Competency Modeling", Personnel Psychology, Vol. 64 No. 1, pp. 225-262.

Campion, M., Schepker, D., Campion, M. and Sanchez, J. (2020). "Competency modeling: A theoretical and empirical examination of the strategy dissemination process", Human Resource Management, Vol. 59 No. 3, pp. 291-306.

Catano, V., Darr, W. and Campbell, C. (2007), "Performance Appraisal of Behavior-Based Competencies: A Reliable and Valid Procedure", Personnel Psychology, Vol. 60 No. 1, pp. 201-230.

Chadwick, C. and Flinchbaugh, C. (2020). "Searching for Competitive Advantage in the HRM/Firm Performance Relationship. Academy of Management Perspectives, ahead-of-print: https://doi:10.5465/amp.2018.0065

De Vos, A., De Hauw, S. and Willemse, I. (2015), "An integrative model for competency development in organizations: The Flemish case", The International Journal of Human Resource Management, Vol. 26 No. 20, pp. 2543-2568.

Delery, J.E. and Roumpi, D., 2017. Strategic human resource management, human capital and competitive advantage: is the field going in circles? Human Resource Management Journal, Vol. 27 No. 1, pp. 1-21.

Deloitte (2015) Competency Management at Its Most Competent, Archived from:

https://www2.deloitte.com/content/dam/Deloitte/za/Documents/human-

capital/ZA_Competency_management_at_its_most_competent.pdf

DuHadway, S., Carnovale, S. and Kannan, V.R. (2018), "Organizational communication and individual behavior: Implications for supply chain risk management", Journal of Supply Chain Management, Vol. 54 No. 4, pp. 3-19.

Dumay, J. and Guthrie, J. (2017), “Involuntary disclosure of intellectual capital: is it relevant?", Journal of Intellectual Capital, Vol. 18 No. 1, pp. 29-44. 
Eric Soderquist, K., Papalexandris, A., Ioannou, G. and Prastacos, G. (2010), "From task-based to competency-based: a typology and process supporting a critical HRM transition", Personnel Review, Vol. 39 No. 3, pp. 325-346.

Fitri, H., Nugraha, A.T., Hakimah, Y. and Manihuruk, C. (2019), Strategic management of organizational knowledge and competency through intellectual capital, Polish Journal of Management Studies, Vol. 19 No. 2, pp. 132-141.

Friedman, B.A. (2019), "Hospitality, tourism, and events industry competency model: Human resource management implications, in Strategic Innovative Marketing and Tourism (pp. 49-56). Springer, Cham.

Garman, A.N., Standish, M.P. and Kim, D.H., 2018. Enhancing efficiency, reliability, and rigor in competency model analysis using natural language processing. The Journal of Competency-Based Education, 3(3), p. e01164.

Gentry, W. and Sparks, T., (2011). A Convergence/Divergence Perspective of Leadership Competencies Managers Believe are Most Important for Success in Organizations: A Cross-Cultural Multilevel Analysis of 40 Countries. Journal of Business and Psychology, 27(1), pp. 15-30.

Gogan, L.M., Artene, A., Sarca, I. and Draghici, A., 2016. The impact of intellectual capital on organizational performance. Procedia-social and behavioral sciences, 221, pp. 194-202.

Gonzalez, R. V. D. and Melo, T. M. (2017) 'Linkage between dynamics capability and knowledge management factors', Management Decision, 55(10), pp. 2256-2276

Guo, Y., Jasovska, P., Rammal, H. G. and Rose, E. L. (2020), "Global mobility of professionals and the transfer of tacit knowledge in multinational service firms", Journal of Knowledge Management, Vol. 24 No. 3, pp. 553-567.

Hanna, A.S., Ibrahim, M.W., Lotfallah, W., Iskandar, K.A. and Russell, J.S., 2016. Modeling project manager competency: an integrated mathematical approach. Journal of Construction Engineering and Management, 142(8), p. 04016029.

Hickey, C., 2018. Building employee skills capacity-focusing on support staff. Independent Education, 48(1), p. 22.

Hollenbeck, G., McCall, M. and Silzer, R. (2006), "Leadership competency models", The Leadership Quarterly, Vol. 17 No. 4, pp. 398-413.

Hussinki, H., Ritala, P., Vanhala, M. and Kianto, A. (2017), "Intellectual capital, knowledge management practices and firm performance", Journal of Intellectual Capital, Vol. 18 No. 4, pp. $904-$ 922.

Ji, J. and Ma, L., 2019, February. Research on the Relationship Among Intellectual Capital, Learning from Failures and Enterprise Innovation Performance. In 2018 International Symposium on Social Science and Management Innovation (SSMI 2018). Atlantis Press.

Jordão, R. V. and Novas, J. C. (2017), "Knowledge management and intellectual capital in networks of small- and medium-sized enterprises", Journal of Intellectual Capital, Vol. 18 No. 3, pp. 667-692.

Kazmi, A. (2008), "A proposed framework for strategy implementation in the Indian context", Management Decision, Vol. 46 No. 10, pp. 1564-1581.

Klink, M. and Boon, J. (2003), "Competencies: the triumph of a fuzzy concept", International Journal of Human Resources Development and Management, Vol. 3 No. 2, pp. 125-137. 
Kwok, F., Sharma, P., Gaur, S.S. and Ueno, A. (2019), "Interactive effects of information exchange, relationship capital and environmental uncertainty on international joint venture (IJV) performance: An emerging markets perspective”, International Business Review, Vol. 28 No. 5, p. 101481.

Lee, R. (2009), "Social capital and business and management: Setting a research agenda", International Journal of Management Reviews, Vol. 11 No. 3, pp. 247-273.

Long, C. and Ismail, W. (2011), "An analysis of the relationship between HR professionals' competencies and firms' performance in Malaysia", The International Journal of Human Resource Management, Vol. 22 No. 5, pp. 1054-1068.

Massaro, M., Dumay, J., Garlatti, A. and Dal Mas, F. (2018), "Practitioners' views on intellectual capital and sustainability”, Journal of Intellectual Capital, Vol. 19 No. 2, pp. 367-386.

Muratbekova-Touron, M. (2009), "Why a multinational company introduces a competency-based leadership model: a two-theory approach", The International Journal of Human Resource Management, Vol. 20 No. 3, pp. 606-632.

Naulleau, M. (2019), "When TM strategy is not self-evident: Action research with a mid-sized French company on organizational issues affecting TM strategy", Management Decision, Vol. 57 No. 5, pp. $1204-1222$.

Ngo, H., Jiang, C. and Loi, R. (2014), "Linking HRM competency to firm performance: an empirical investigation of Chinese firms", Personnel Review, Vol. 43 No. 6, pp. 898-914.

Nourani, M., Chandran, V.G.R., Kweh, Q.L. and Lu, W.M. (2018), "Measuring human, physical and structural capital efficiency performance of insurance companies", Social Indicators Research, Vol. 137 No. 1, pp. 281-315.

Paoloni, M., Coluccia, D., Fontana, S. and Solimene, S. (2020), "Knowledge management, intellectual capital and entrepreneurship: a structured literature review", Journal of Knowledge Management, Vol. 24 No. 8, pp. 1797-1818.

Papa, A., Dezi, L., Gregori, G. L., Mueller, J. and Miglietta, N. (2018), "Improving innovation performance through knowledge acquisition: the moderating role of employee retention and human resource management practices", Journal of Knowledge Management, Vol. 24 No. 3, pp. 589-605.

Pasban, M. and Nojedeh, S.H. (2016), "A Review of the Role of Human Capital in the Organization", Procedia-social and behavioral sciences, 230, pp. 249-253.

Podmetina, D., Soderquist, K.E., Petraite, M. and Teplov, R. (2018), "Developing a competency model for open innovation", Management Decision, Vol. 56 No. 6, pp. 1306-1335

Rodriguez, D., Patel, R., Bright, A., Gregory, D. and Gowing, M. (2002), "Developing competency models to promote integrated human resource practices", Human Resource Management, Vol. 41 No. 3, pp. 309-324.

Salvi, A., Vitolla, F., Giakoumelou, A., Raimo, N. and Rubino, M. (2020), "Intellectual capital disclosure in integrated reports: The effect on firm value", Technological Forecasting and Social Change, Vol. 160, p. 120228.

Sanchez, J. and Levine, E. (2009), "What is (or should be) the difference between competency modeling and traditional job analysis?", Human Resource Management Review, Vol. 19 No. 2, pp. 53-63.

Seidel, A., Saurin, T.A., Marodin, G.A. and Ribeiro, J.L.D. (2017), "Lean leadership competencies: a multi-method study", Management Decision, Vol. 55 No. 10, pp. 2163-2180 
Shan, L., Dan, L. and Qiu, Y.M. (2020), "Study of the impact mechanism of inter-organizational learning on alliance performance - with relationship capital as the mediator", Neural Computing and Applications, Vol. 32 No. 1, pp. 117-126.

Shet, S., Patil, S. and Chandawarkar, M. (2019) "Competency based superior performance and organizational effectiveness", International Journal of Productivity and Performance Management, Vol. 68 No. 4, pp.753-773.

Shet, S., Patil, S. and Chandawarkar, M. (2017). "Framework for methodical review of literature on leadership competencies," Cogent Business \& Management, Vol. 4 No 1, pages 1309123-130, January.

Shet, S. V (2019). "Strategic talent management - contemporary issues in international context", Human Resource Development International, Vol. 22 No.4, pp. 98-102

Shippmann, J., Ash, R., Batjtsta, M., Carr, L., Eyde, L., Hesketh, B., Kehoe, J., Pearlman, K., Prien, E. and Sanchez, J. (2000), "The Practice of Competency Modeling”, Personnel Psychology, Vol. 53 No. 3, pp. 703-740.

Stone, T., Webster, B. and Schoonover, S., (2013). "What Do We Know About Competency Modeling?", International Journal of Selection and Assessment, Vol. 21 No. 3, pp. 334-338.

Vakola, M., Eric Soderquist, K. and Prastacos, G., (2007), "Competency management in support of organisational change”, International Journal of Manpower, Vol. 28 No. 3/4, pp. 260-275. 
Table 1: Demographics of respondents

\begin{tabular}{|l|l|l|l|}
\hline$\#$ & Industry & $\begin{array}{l}\text { Type } \\
\text { Organization }\end{array}$ & Respondent title \\
\hline 1 & Information Technology & MNC & Manager - Talent Management \\
\hline 2 & Information Technology & MNC & HRBP Manager \\
\hline 3 & Information Technology & MNC & Lead- Talent Engagement \\
\hline 4 & Consulting & MNC & Consultant - Change \& People \\
\hline 5 & Conglomerate & MNC & Head - OD \\
\hline 6 & Conglomerate & MNC & Head- OD \\
\hline 7 & IT and ITES & MNC & Consultant - People practice \\
\hline 8 & Paints & Indian & General Manager - HR \\
\hline 9 & Steel & Indian & Unit Head \\
\hline 10 & Banking \& Financial Services & MNC & AVP - Treasury \\
\hline 11 & Banking \& Financial Services & MNC & Branch Manager \\
\hline 12 & Conglomerate & Indian & GM - Human Capital \\
\hline 13 & Power \& Electricals & Indian & CEO \\
\hline 14 & Infrastructure & Indian & CEO \\
\hline 15 & Pharmaceuticals & Indian & Plant Head \\
\hline 16 & Pharmaceuticals & Indian & Sales Manager \\
\hline 17 & Chemicals & MNC & Director - Office \\
\hline 18 & Textiles & Indian & Chief Marketing Officer \\
\hline
\end{tabular}

Table 2: Factors influencing competency modeling(CM) implementation 


\begin{tabular}{|c|c|}
\hline \multicolumn{2}{|r|}{ Factors influencing Competency Modeling Implementation } \\
\hline \multirow{9}{*}{ 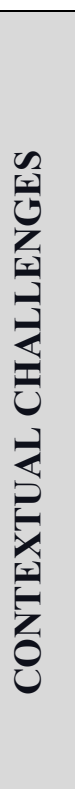 } & Inadequate HR proficiency in implementation \\
\hline & Unaddressed organization-specific challenges \\
\hline & Lack of specificity of competencies \\
\hline & Lack of contextual relevance of competencies \\
\hline & Improper use of proficiency level of competencies \\
\hline & Lack of validity in competencies \\
\hline & Conflicts in the universal application of CM \\
\hline & Issues with competency-based HRM (CHRM) \\
\hline & The criticality of competencies \\
\hline \multirow{8}{*}{ 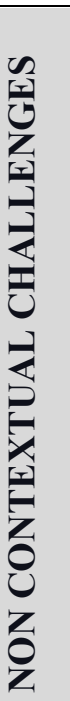 } & Ineffective communication \\
\hline & Lack of stakeholders' involvement \\
\hline & Lack of leadership drive \\
\hline & No link to vision and strategy \\
\hline & Resistance from employees \\
\hline & Inadequate cost-benefit analysis \\
\hline & Inadequate organizational readiness \\
\hline & Inadequate budgets and resources allocation \\
\hline
\end{tabular}


Table 3: Framework for competency modeling(CM) implementation

\begin{tabular}{|c|c|c|c|}
\hline & Change align ment & Operational alignment & Behavioral alignment \\
\hline Direction setting & $\begin{array}{l}\text { Is the organization clear on its } \\
\text { rationale, direction, and path to } \\
\text { bring change through CM? }\end{array}$ & $\begin{array}{l}\text { Has the organization set clear specific } \\
\text { goals for both the strategic and } \\
\text { operational objectives of CM? }\end{array}$ & $\begin{array}{l}\text { Has the organization laid out a } \\
\text { specific approach to stakeholders } \\
\text { regarding the communication, } \\
\text { learning, and decision-making } \\
\text { related to the CM process/ } \\
\text { implementation? }\end{array}$ \\
\hline $\begin{array}{l}\text { Selling } \\
\text { and negotiation }\end{array}$ & $\begin{array}{l}\text { Is everyone within the } \\
\text { organization convinced about } \\
\text { the soundness/ rationality of the } \\
\text { proposed changes using CM? }\end{array}$ & $\begin{array}{l}\text { Has the organization acquired the } \\
\text { resources and agreements from both } \\
\text { downstream and upstream departments } \\
\text { on all aspects of CM? }\end{array}$ & $\begin{array}{l}\text { Do all stakeholders in the } \\
\text { organization accept the approach to } \\
\text { communication, learning and } \\
\text { decision making? }\end{array}$ \\
\hline $\begin{array}{l}\text { Control } \\
\text { and monitoring }\end{array}$ & $\begin{array}{l}\text { Does everyone know how CM } \\
\text { initiatives are implemented and } \\
\text { monitored with milestones? }\end{array}$ & $\begin{array}{l}\text { Is the organization aware of how their } \\
\text { plans and processes in CM match with } \\
\text { the performance expectations? }\end{array}$ & $\begin{array}{l}\text { Are all stakeholders in CM aware of } \\
\text { how their current behaviors and } \\
\text { attitudes align with the set } \\
\text { approaches to communication, } \\
\text { learning, and decision-making? }\end{array}$ \\
\hline
\end{tabular}

